\title{
Antes de começarem as aulas: polêmicas e discussões na criação do Conservatório Dramático e Musical de São Paulo
}

\author{
Ailton Pereira Morila (UNICEP, São Paulo, SP) \\ apmorila@gmail.com
}

Resumo: 0 Conservatório Dramático e Musical de São Paulo foi fundado em 1906, fruto da iniciativa de vários músicos do Estado de São Paulo. 0 caminho para sua fundação foi de conflitos, lutas e opiniões divergentes, mas também de associações e objetivos comuns. 0 objetivo deste artigo é ressaltar esta trajetória, procurando destacar sua intima ligação com as discussões acerca do papel da música e dos músicos na sociedade em transformação.

Palavras-chave: Conservatório Dramático e Musical de São Paulo; música e sociedade; organização profissional, ensino musical.

\section{Before lessons begin: controversies and quarrels around the creation of the Conservatório Dra- mático e Musical of São Paulo}

Abstract: The Conservatório Dramático e Musical of São Paulo was established in 1906 as an initiative of some musicians of the State of São Paulo, Brazil. The way for its foundation was one of divergent opinions, fights and conflicts, but also of common associations and objectives. This article aims at to tracing its trajectory, focusing on the quarrels concerning the position of music and musicians in a society in transformation.

Keywords: Conservatório Dramático e Musical of São Paulo; music and society; professional organization, music teaching.

\section{1- Introdução}

Atrás do Teatro Municipal, com entrada na Avenida São João existe um edifício que normalmente passa despercebido. Observando algum tempo, é possivel notar um entra e sai de pessoas com seus instrumentos musicais protegidos por caixas das mais variadas formas e tamanhos. É o Conservatório Dramático e Musical de São Paulo.

Se hoje ele é só mais um prédio no centro velho de São Paulo, só mais uma escola de música dentre tantas outras que povoam e proliferam em uma metrópole que não para de crescer, outrora foi a escola onde Mário de Andrade e Francisco Mignone - só para citar dois importantes nomes - estudaram e lecionaram.

0 Conservatório Dramático e Musical de São Paulo, inaugurado em 12 de março de 1906 com a presença do então Presidente do Estado Jorge Tibiriçá e outras autoridades, funcionou inicialmente na Rua Brigadeiro Tobias, onde morou a Marquesa de Santos, mudandose para a Av. São João em 1909. Seu fundador oficial foi Pedro Augusto Gomes Cardim e no primeiro corpo docente encontramos nomes como:
Luigi Chiaffarelli, Antonio Carlos Ribeiro de Andrada Machado e Silva Junior, João Gomes de Araújo, Giulio Bastiani, Paulo Florence, Felix Otero, Dr. Luiz Pinheiro da Cunha, Dr. Wenceslau de Queiroz, Augusto César Barjona, Hyppolito da Silva. Todos, membros de destaque do ambiente artístico daquelle ${ }^{1}$ tempo. (ALMEIDA, 1931, p.57).

Os primeiros no departamento musical, enquanto que os quatro últimos no departamento artístico a quem se soma ainda o fundador, Pedro Augusto Gomes Cardim. Além destes nomes, ainda outros como Guido Rocchi, Paulo Tagliaferro, Adolpho de Araújo, Gomes Cardim, Henri Ruegger e G. Foschini fizeram parte da primeira congregação, enquanto outros como Zulmira de Andrada Machado, Anna Freymann, Olympia Catta Preta, Olga Massucci, Felippe De Lorenzi, Gervazio de Araújo e José de Souza Lima foram contratados. (ALMEIDA, 1931, p.57).

Estes e outros nomes - que por motivos vários não participaram da fundação do conservatório - foram sujeitos das transformações sofridas por São Paulo e pelo Brasil nas últimas décadas do século XIX e na primeira do século XX. Transformações não só no aspecto visivel, nas casas, ruas, avenidas, prédios, praças e transportes, mas tam- 
bém nos aspectos culturais e sociais. Coelho Neto (Apud ALMEIDA, 1931, p.74-75), ao assinar o livro de ouro do Conservatório, em 1913, sintetiza:

\begin{abstract}
Entrando nesta casa sob flores tive a suave fortuna de ouvir os alumnos que nella estudam e delles tive a prova de que o sonho de meus irmãos em Arte começa a tornar-se realidade. Conheci São Paulo no tempo das construcções coloniaes e, á noite, por entre a nevoa da garôa, soavam docemente as serenatas romanticas. Retirei-me, como que foi commigo o som da ultima guitarra... Annos depois tornei. A cidade das taipas era a maravilha de hoje... Os palacios porem, pelo silencio que os cercava, na espessura do arvoredo, lembravam o da lenda da princesa adormecida... Agora resôam vozes, vibram melodiosos instrumentos, a musica desperta a cidade... É a nova cultura artistica que opera o desencantamento e, graças a este instituto, dentro em breve, o genio paulista, que soube fazer o ninho formoso, de marmore e de ouro, soltará delle, para gloria da Arte brasileira, o bando de rouxinóes que afinam as vozes nesta casa que, modestamente, sem rumor, está preparando um nucleo de artistas dignos da terra de Carlos Gomes.
\end{abstract}

São Paulo trabalha como as abelhas - mysteriosamente... e, como appareceu, do dia para a noite, grande no progresso ha de surgir improvisamente, grande na cultura: tem o que é necessario: talento, iniciativa e o amor de seus filhos.

Para Coelho Neto a São Paulo "das taipas" transformouse em São Paulo dos Palácios da "noite para o dia". Apesar de assim parecer para quem permaneceu longe de São Paulo por um tempo, a transformação perpetrada em São Paulo não se fez isenta de polêmicas e conflitos como mostra a historiografia. A organização musical que culminou na inauguração do Conservatório Dramático e musical de São Paulo também não.

\section{2 - Entre polêmicas e confraternizações: or- ganização e profissionalização}

$\mathrm{Na}$ "Capital Artística", como costumavam chamar São Paulo, o viver de música encontrava-se longe de ser fácil e as rivalidades afloravam:

Assim, as relações dos músicos com o público paulistano, muitas vezes tensas, envolviam igualmente algum tipo de atrito entre os próprios músicos, implicado nas disputas por clientela e aceitação social. 'Trabalhando para viver', os músicos por vezes relacionavam-se de forma bem pouco fraterna. (GONÇALVES, 1995, p.1863)

Entretanto, ou até mesmo por isso, as polêmicas gestadas no final do século XIX - e que permanecem, embora ressignificadas, no século $X X$ - não podem ser vistas simplesmente como disputa por público ou alunos. Devem ser encaradas também como disputas em torno do papel da música nesta sociedade em transformação, e com ela o papel do músico. Há que se lembrar ainda o que VENTURA (1991, p.80) percebeu para as polêmicas entre Romero e seus contemporâneos:

\footnotetext{
Afinal, na ótica de Romero e de seus contemporâneos, cabia a polêmica contribuir para o processo de seleção e depuração das obras e escritores, lançados ao público na luta pela existência.
}

Inserida no contexto da ciência evolucionista, a polêmica - típica do final do século XIX - inicia também um debate que não é apenas entre gerações, entre o novo e o velho, como antes, mas no interior da própria geração, como observou VENTURA (1991, p.152), na tentativa "de se formarem distinções teóricas e políticas..."2

Portanto, as disputas em torno da música realizadas através das polêmicas - mormente publicadas nos periódicos - eram disputas em torno do papel da música na sociedade, muito embora algumas delas encobrissem disputas por público, alunos e prestígio.

Deixemos a polêmica por enquanto. Entremos na casa de Antonio Carlos de Andrada e sua esposa, a "distincta professora D. Zulmira". Na noite de 15 de agosto de 1897 confraternizavam-se vários convidados, entre eles Chiaffarelli que acompanhou ao piano juntamente com Antonio Carlos, D. Zulmira cantando composições várias e entre elas algumas do cônjuge. A notícia foi escrita por C. d. $\mathrm{M}^{3}$., que também foi convidado.

Era comum, segundo Pelágio Lobo, Elias Alvares Lobo ouvir na sua janela:

\footnotetext{
- Elias! Elias! ... é o Américo. [Américo de Campos]

Pouco depois estavam os dois na sala.

0 que é que você tem de bom para tocar? Missa, não!

Vamos ouvir uma toada antiga, uma valsa de Itú, uma cantiga qualquer, uma modinha da sua invenção. Começava a tocata e Américo descobrindo a um canto um violino, tomava-o, punha-se a encaixar suas arcadas nos compassos do piano, ornamentandoo de variações inesperadas. Entusiasmavam-se, riam, folgavam, despertavam a vizinhança com aquelas tiradas boemias. (Correio Paulistano, 1950 apud SERGL, 1991, p.102-103)
}

Em A Música para todos foi escrito um artigo humoristico sobre um banquete oferecido pelos músicos de São Paulo a concertistas portugueses, em 1897, revelando de forma bem humorada as caracteristicas dos presentes. As referências, quer seja o modo de falar - Chiaffarelli e sua "original linguagem" - quer seja a profissão - Antonio Leal "esquecera" seu martelo de leiloeiro - mostram traços pessoais que só a convivência é capaz de perceber. ( $A$ Música para todos, 1896 n. 32-33, p.267).

Estes episódios mostram a existência, para além das polêmicas, de um círculo de amizades, ou pelo menos de conhecidos e colegas reunidos em torno da música.

Se em muitos assuntos eles divergiam, em um ponto todos concordavam: havia chegado o momento de se organizar. Vejamos esta passagem de outro artigo:

Uma tarde um compositor de 'couplets' entrou n'uma café concerto onde estavam muito em voga as suas cançonetas e sentou se a uma mesa.

0 creado perguntou-lhe o que queria.

- Nada, vim simplesmente assistir á interpretação das minhas canções.

- Mas é necessario 'consumir', diz-Ihe o creado.

Interveio no caso o dono do café que convida egualmente o fregues a 'consumir' ou abandonar o local que tinha tomado.

- Mas, senhor, eu sou o auctor das canções.

- Deilal-o ser

Pois bem, tragam-me um copo d'agua com assucar, mas por meu turno, prohivo-os que cantem as cançonetas de que sou ou [sic] auctor e que estão annunciadas no programma. 
0 dono do café não fez caso da prohibição e isso deu origem a que intentassem um processo cujo resultado foi elle condenado a cem francos de indemnização.

Logo que se Ihes offereceu ensejo reuniram-se diversos escriptores, que acordaram nas bases para formnar uma associação.

Eis porque é costume dizer-se que d'um copo d'agua com assucar nasceu a sociedade actual de auctores, editores e compositores de musica. (A Paulicéia, 1896, p.7)

Este episódio, colocado em tom de humor pelo periódico, expõe a situação dos músicos e indica que associação entre eles parecia ser uma solução viável para problemas de ordem autoral, entre outros. A profissionalização traria certos direitos, enquanto as associações garantiriam e expandiriam esses direitos. Este humorismo coloca bem, não só a posição do músico na sociedade, como também serve como paradigma da profissionalização do período: existia uma preocupação em criar associações, agremiações, organizações que assegurassem direitos e criassem um sentido de profissionalismo partindo dos mais diversos setores da sociedade.

VENTURA (1991, p.102-103) procura evidenciar como as disputas políticas e sociais que cerceavam o debate dos literatos cede lugar a preocupação puramente classista. Reunidos em torno da Revista Brasileira, estes escritores ${ }^{4}$ fundaram a Academia Brasileira de Letras em 1897:

\footnotetext{
Com a estabilização política a partir de 1898, os escritores deixaram de lado a luta pela regeneração nacional, caracteristica da 'geração de 1870'. Sua missão se tornara literária no sentido estrito, relacionada à afirmação profissional do critico e do escritor, o que se manifestou na criação da Academia em 1897. A iniciativa partiu do grupo que se refletia na Revista Brasileira, da qual Veríssimo era diretor, para debater temas estéticos e literários, sem o envolvimento de questões políticas. Os acadêmicos buscavam o reconhecimento da criação literária e adotavam certa distância entre a sociedade e a sua própria esfera, mas não mais aceitavam a marginalidade ou o engajamento.
}

Da mesma maneira, Denice CATANI (1989) apresenta o quadro para os professores em São Paulo, que em torno da Associação Beneficente do Professorado Público de São Paulo criada em 1901 e da Revista de Ensino, órgão da associação, criada em 1902, procuraram nortear suas práticas educacionais, servindo também como porta-voz dos interesses de classe.

Quanto aos músicos de São Paulo, uma das primeiras tentativas foi empreendida por Elias Alvares Lobo e seu cunhado, Tristão Mariano da Costa. Através de ofícios enviados de Itu, onde residiam, convocaram os músicos da província para um congresso a realizar-se no dia 26 de setembro de 1875. (SERGL, 1991, p.86-87).

Segundo SERGL (1991, p.87) o "congresso coroou-se de pleno êxito", sendo apresentados dois métodos de ensino e criada uma comissão que ficou encarregada de registrar os estatutos da nova sociedade. Participaram deste congresso além de Elias Alvares Lobo e Tristão Mariano da Costa, Antonio José de Almeida, Luis Mauricio, Gabriel Giraudon, Melchiades da Boa-Morte Trigueiros e Américo de Campos, entre outros. (GONÇALVES, 1995, p.189). Esta sociedade, entretanto, não logrou, e a imprensa da época não conseguiu identificar o porquê. (SERGL, 1991, p.87).

\section{Em 1883 aparece uma nota n'A Provincia de São Paulo:}

\section{Sociedade Artística Beneficente}

Pergunta-se aos membros da directoria d'esta associação quando pretendem convocar Assembléia Geral para darem conta de seus atos: pois que, ha trez annos, mais ou menos, nada sabemos relativamente á marcha da mesma sociedade.

Alguns sócios inimigos das directorias em prorrogação." (p.1)

Trata-se da mesma associação ou era outro caso de organização frustrada?

Em 1889, uma tentativa de se criar um conservatório por iniciativa de alguns professores liderados por Antonio Carlos Junior, da qual participaram Antonio Carlos Junior, João Gomes de Araújo, Antonio Leal, Santini, Hollender, Gabriel Giraudon, Bastiani, Gustavo Wertheimer, Barreire, também fracassou. Esta tentativa frustrada gerou por parte da imprensa, uma crônica carregada de humor:

\begin{abstract}
Antonio Carlos Junior, presidindo a reunião, nem bom a declara aberta e já é contestado por João Gomes; ato contínuo, se retira. João Gomes pede a palavra ao presidente sem que haja presidente; a palavra Ihe é concedida mas as interrupções são constantes: em vários momentos exige-se que retire ou corrije afirmações que fez, e o Sr. Festa pede até mesmo licença 'para cantar uma aria dramatica de sua composição'. No momento da ária, Antonio Carlos, que inexplicavelmente volta a estar presente, sussurra para Américo de Campos, em seu português acentuadamente lusitano: 'O Amareico, o Festa não é de festa! Hom'esta? Isto não presta!'. E se retira 'com uma revista franceza em baixo do braço e um sorriso nos labios'. João Gomes continua como orador até que Santini peça para falar 'due palavri'; seu português macarronico provoca protestos dos demais: 'Falle portuguez, do contrario apanha!' Vencido, Santini volta a sentar-se, choroso. 0 adiantado da hora faz com que Wertheimer informe, em português de acento germânico: 'Eu va emborra porque eu va a Strasella!'; aproveitando a brecha, Hollender pede 'parra lerr um artigue de critica musicale!'. Frente a essa verdadeira ameaça, 'todos saem correndo'. Todos, com exceção de Américo de Campos que, ao som das primeiras palavras do artigo de Hollender, desperta do sono que tirava nas galerias. (Apud GONÇALVES, 1995, p.190-191)
\end{abstract}

Mas o humor é apenas uma parte do discurso: o artigo culpa a inabilidade dos músicos pelo fracasso da tentativa. Diferentemente do texto publicado pela $A$ Música para todos que ressaltava as idiossincrasias dos presentes no intuito de mostrar como foi animado e concorrido o banquete (1896 n. 32-33, p.267), neste, descambando para o sarcasmo aponta características que impedem a realização de algo concreto. A falta de comunicação, a desorganização, as intrigas internas, a incapacidade de pensar noutra coisa a não ser música, e até mesmo a existência de várias nacionalidades são apontadas como fatores do fracasso.

Em 1897, um movimento que contava com Luigi Chiaffarelli, Felix de Otero, Antonio Leal, Mello Abreu, Luiz Levy, Victor Rondelli, Leopoldo de Freitas, João Escobar, Almeida Junior, Ezequiel Ramos Junior, Augusto Barjona, Antonio Carlos, Rugger e Carlos de Campos tentava criar um club artístico. Até mesmo uma comissão para análise 
do projeto de estatuto foi criada. (A Música para todos, 1897, 288). Em agosto de 1898 o mesmo periódico se mostrou estupefato:

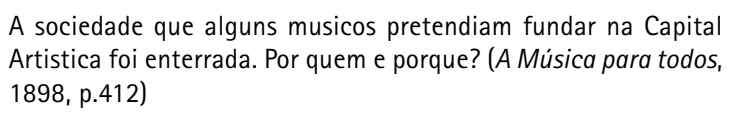

A sociedade que alguns musicos pretendiam fundar na Capital Artistica foi enterrada. Por quem e porque? (A Música para todos, 1898, p.412)

Exceção a estas tentativas frustradas é a própria existência do periódico A Música para todos, que de 1896 a 1899, circulou na capital de São Paulo, trazendo a agenda artística da cidade, discussões e assuntos referentes a música. Este mesmo periódico, através de seus colaboradores, encampou as expectativas dos músicos na organização profissional. Por ocasião da fundação da Academia Livre de Música do Rio de Janeiro, em 1897 publicou, em tom de lamento:

\footnotetext{
Aqui continuamos sem conservatório official, nem academia livre; ainda vivemos na espectativa de melhores tempos para se cogitar da educação artística do povo.

Pobre 'Capital artística'! (A Música para todos, 1897, p.181)
}

No mesmo tom, A Paulicéia publicara um ano antes:

Pensou-se, discutiu-se e cremos que até se projectou n'esta terra um theatro municipal. Um jornal, que não se publica já, pediu conservatório, aulas de música e, por essa epocha d'aqui dissemos que theatro apenas era um bom começo mas que provavelmente nem isso não teremos tão cedo.

Infelizmente o tempo veio demonstrar que prophetisamos. (A Paulicéia, 1896, p.7)

Os músicos teriam de aguardar, até 1906, a criação do Conservatório Dramático e Musical de São Paulo.

Pedro Augusto Gomes Cardim, então vereador municipal, apresenta um projeto para a criação do Conservatório Dramático e Musical de São Paulo. Este projeto, que inicialmente propunha o custeio por parte da municipalidade, sofreu alterações, e ao município caberia apenas uma subvenção. Também foi frustrada a tentativa de fazê-lo funcionar, provisoriamente, no Teatro Municipal. Tentativas de loterias - proibidas na Constituição, mas abriu-se uma exceção - se mostraram infrutíferas. 0 porquê, entretanto não foi explicado. Após a primeira reunião, realizada no Club Internacional, foi nomeada uma comissão assim constituída: Presidente, A. de Lacerda Franco; Tesoureiro, Carlos de Campos; Diretor secretário, Pedro Augusto Gomes Cardim e para o primeiro caixa, companhias teatrais e líricas cederam a bilheteria de alguns dos seus espetáculos, bem como uma quermesse foi realizada. A primeira reunião foi realizada em 1/02/1906 no antigo prédio da Marquesa de Santos, e foi inaugurado oficialmente em 12 de março de 1906. (ALMEIDA, 1931, p.53-56).

Os cursos inicialmente abertos foram: italiano, aritmética, literatura, dicção no curso dramático, rudimentos de música, solfejo, harmonia, piano, canto coral, canto, harpa e instrumentos de sopro. Realizado, enfim, o antigo sonho dos músicos de São Paulo. (ALMEIDA, 1931, p.56).
Estas tentativas de organização - frustradas ou não - implicam em uma tentativa de redefinição do campo de atuação dos próprios envolvidos. BASTOS (1995, p.54) afirma que a música ocidental encontra nos concertos - que a reinventa - e nos conservatórios - que a conserva - "os templos ideais de sacralização, cultivo e consensualização".

VENTURA (1991, p.116) vem alertar, para o campo literário, esta condição:

Para reconhecer a autoridade da critica e do ensino da literatura, era preciso definir o seu campo de competência, de acordo com a identidade 'natural' de seus objetos. 0 estabelecimento de atividades profissionais, relacionadas à literatura, depende da rede de inclusões e exclusões, por meio da qual se formam as matrizes institucionais que regulamentam as práticas de leitura e o cânone das obras integradas à história literária.

Como esta rede de inclusões e exclusões se manifesta no campo musical? Qual seria o cânone das obras musicais aceitas pelas "matrizes institucionais"?

Em São Paulo, no final do século XIX e início do $X X$, a posição social do músico em relação a seus pares é objeto de disputa que frequentemente extravasa do círculo de conhecidos para a imprensa.

0 principal objeto de discussões gira em torno das apresentações musicais. Emilio do Lago, ainda em 1866, quando era regente da Orquestra do Teatro, recusou-se a tocar em bailes do Hotel das Quatro Estações, afirmando que "desde que veio para São Paulo ainda não tocou em bailes públicos", posição esta referendada por José Jovita Correa do Lago: "não toco em bailes públicos e não faço parte do numero dos que se contractão para esse fim" (GONÇALVES, 1995, p.180).

Em lado oposto, Gabriel Giraudon não se importava em tocar em bailes, chegando mesmo a dirigir a orquestra do mal-afamado "Alcazar Lyrique" 5 no Rio de Janeiro, antes de vir morar em São Paulo. (GONÇALVES, 1995, p.182).

Da mesma maneira Chiaffarelli se bateu n'A Música para todos com Felix Otero e Gustavo Wertheimer, estes últimos acusando o primeiro de realizar maratonas pianisticas com suas alunas, mais ao modo do espetáculo circense do que de concerto de arte musical (A Música para todos, 1897).

Entre a luta pela sobrevivência e a luta pela profissionalização, os músicos caminhavam do baile ao concerto, e também do popular ao erudito, como o fez paradoxalmente o próprio Emilio do Lago ao compor músicas mais afeitas ao gosto popular.

De forma similar, Elias Alvares Lobo transitava entre óperas e canções populares, colocando-se ainda entre a República e a Igreja, compondo hinos republicanos e músicas sacras, em um momento em que a Igreja era sinal de monarquia. 
Apesar de o cânone ser composto por obras de caráter erudito, baseadas nas escolas européias ${ }^{6}$, alguns músicos transitavam entre este cânone e música popular, servindo como instrumentos de ligação entre a cultura popular e a cultura erudita (MORILA, 2004).

Se a disputa entre o que compor e aonde se apresentar não era consenso, outra questão era um pouco mais clara. Tomemos este artigo intitulado "Entendidos Musicais":

Não há cidade que não apresente alguns especimens de entendidos em tudo, pseudo-sabios que em tudo mettem o bedelho, intrometendo-se em conversas, apresentando uma alta opinião, em ar dogmático, como quem pisa em terreno seguro, comquanto a socapa, de si para si, se considera uma nullidade na matéria em que discute.

0 artigo continua citando um exemplo jocoso que teria acontecido no dia seguinte da representação da ópera $R i-$ goletto. Estando o "entendido musical" na casa Levy, trava diálogo com Alex. Vale a pena transcrever um trecho:

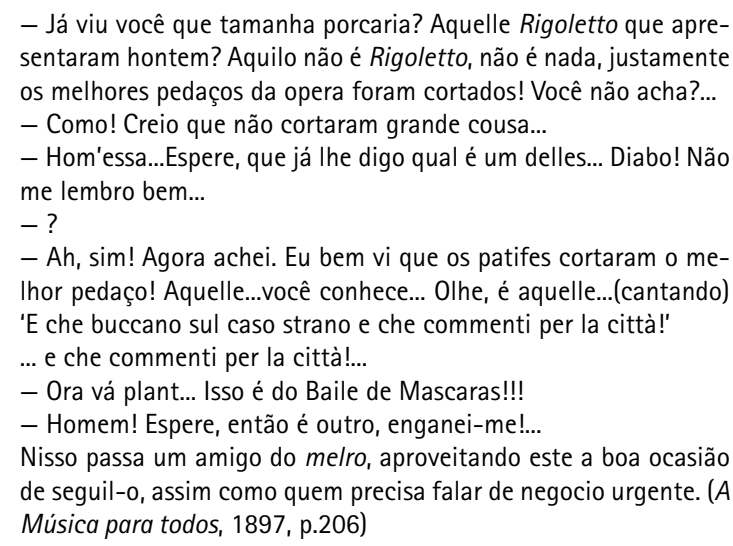

Quem poderia ser considerado um crítico musical? Quem poderia ser considerado um músico? No artigo "Músicos amadores", Alfredo Camarate busca separar os músicos profissionais, artistas que aprenderam seu ofício de maneira formal, em escolas, conservatórios ou com renomados professores, e os músicos amadores que aprenderam na prática. Comparando o músico amador com os tuberculosos pulmonares (pois não há cidade populosa que não os tenha), explica em tom sarcástico sua origem:

Como nasce o musico amador?

Homem, nasce como todos os outros: chorando e chuchando no dedo.

Musico, desenvolve-se com a velocidade dos cogumelos. Pôe um dia o dedo n'um teclado de piano e fez-se musico amador; o que é muito differente de amador de musica.

Inicia as suas lides artísticas com o lundu, o lundu clássico, que se chama lundu, como se poderia chamar outra cousa.

Depois de castigar as oito teclas, em que se desenvolve o lundu, o musico amador conhece que pode manejar dous accordes; dó, $\mathrm{mi}$, sol, dó e sol, si, ré, fá. Animado com estes progressos, de que é que suppõem que o amador se lembra? (A Música para todos, 1899, p.554)

0 autor continua ridicularizando e menosprezando este músico que aprende na prática. Outro elemento entra na história: um músico amador mais adiantado, que lhe en- sina outros acordes, outros tons. A falta de nomenclatura erudita é também alvo de piada:

Continua a estudar, apenas com os elementos que possue, auxiliando o furabolos com o pai de todos e o seu vizinho. No fim de três mezes já o nosso maestro faz passos oitavados, empregando o míminho e o matapiolhos.

Um dia, n'um arroubo inspirado, deu taes reviravoltas com tres dedos, que dá com o mordente. Acha sublime e, como na estudou a artinha, baptisa este passo com o nome de saca-rolhas. Dálli em diante não há meio que não acabe pelo tal saca-rolhas. ( $A$ Música para todos, 1899, p.554)

Aqui, revela o nome dos dedos e dos movimentos pianísticos no jargão popular. Na seqüência do artigo, e em determinado momento o autor sentencia:

\begin{abstract}
Se o leitor tiver a desgraça de se encontrar com um destes amadores, dê-lhe desapiedadamente com um cacete, que eu comprometto-me a ir advogar-Ihe a causa, comprometendo-me também a faze-lo sahir do tribunal em triumpho das bênçãos de todas as famílias de S. Paulo e arrabaldes! (A Música para todos, 1899, p.554)
\end{abstract}

É notável a forma como, neste artigo, ao mesmo tempo em que promove a separação entre duas classes de músicos - os profissionais e os amadores, estes devendo ser metaforicamente espancados "com cacete", ou seja, excluídos do universo musical paulistano - Alfredo Camarate deixa registrado todo o processo de aprendizado informal que o músico popular enfrenta, registrando inclusive nomes populares para movimentos musicais (Sacarrolhas, soluço), melodias e ritmos consagrados no popular (lundu, polca, modinhas, contradanças, trechos de óperas), e comparando-o a outros saberes populares como o curandeirismo.

É mesmo interessante esta analogia do músico popular com o curandeiro. Ao analisar a produção da razão médica no século XIX, J. G. GONDRA (2000, p. 521-522) aponta um combate aberto pelos médicos em duas frentes: a interna, onde se combatiam a homeopatia, a helvética e a medicina oriental e; a externa, onde os alvos eram o curandeiro, a benzedeira, os bruxos, mágicos, indígenas, escravos e curiosos. Assim, ao mesmo tempo em que produziam uma razão médica e com ela garantiam o "monopólio sobre a arte de curar", criavam - por assim dizer - os charlatães, i.e., todos que estivessem fora das práticas ditas científicas.

A ironia deste procedimento de criação do charlatanismo e deste artigo em especial, talvez o mais crítico em relação à música e ao músico popular ${ }^{7}$ - é que ele é também o que melhor registra o aprendizado deste músico. Outros registros são por vezes simples demais:

No Natal todo mundo tocava violão, tocava flauta, as crianças gostavam de tocar flautinha de bambu, não sei como tocavam tudo bonitinho naquela flautinha. Quase todo mundo tocava violão de ouvido, a criançada dançava, era bem divertido antigamente (BOSI, 1994, p.375) [grifos meus]

No número seguinte de $A$ Música para todos (1899, p.562), Camarate dá continuidade a sua explanação, 
porém em texto muito mais comedido que o anterior. Talvez por ter sido criticado, ou talvez por ter percebido que esta casta de músicos é de um lado potencial público dos músicos "educados", e de outro lado, constitutivo de grande parte das agremiações musicais brasileiras, ele diminuí o tom de crítica e assume uma postura conciliatória, e às vezes, adulatória:

Não conheço paiz onde as senhoras cheguem a tão alto grao de aperfeiçoamento musical, como no Brazil. Alem do talento natural que possuem para a música, denotão uma educação musical, que não parece a que lhes pode ter fornecido um pais relativamente atrasado no estado theorico da música. Conheço dezenas de senhoras brasileiras que, não só tocão peças difficilimas com summa perfeição, como até leiem, muito discretamente, qualquer música à primeira vista.

As senhoras e as moças de familia merecem aqui um tratamento diferenciado visto que elas constituem parte do público dos concertos, como também consumidoras das partituras editadas.

Mesmo procurando adular determinada parcela destes músicos amadores, Alfredo Camarate sintetiza uma profissionalização crescente do músico no Brasil e em especial em São Paulo, profissionalização esta que incluem uns e excluem outros, valoriza gêneros e estilos em detrimento de outros, em um movimento semelhante ao descrito por VENTURA (1991) para o campo literário e CATANI (1989) para o campo educacional.

Se não se pode eliminá-los - como propôs no primeiro artigo - pode-se separá-los como propõe o final deste segundo artigo:

$E_{1}$ demais, eles já não devem estar macios, com esta critica e faço ponto no assunto; não porque receie que me desacompanhão, mas porque temo que me venhão dar uma serenata, em frente a janela! (A Música para todos, 1899, p.562)

Cantem, toquem e componham, mas longe do ouvido aguçado do músico e do crítico profissional, que se comporta como o autêntico "botafogano" descrito por Lima Barreto8.

\section{3- Considerações finais}

Em 1906 estava delineado um caminho para a música e seu papel na cultura paulista. Os músicos e a música erudita tinham seu lugar privilegiado: o Conservatório Dramático e Musical de São Paulo. A música popular que anteriormente perpassava a cidade começava a se restringir somente à cultura popular.

Aquele músico que escrevia ao mesmo tempo música sacra, música popular e música erudita estava em vias de extinção. Elias Alvares Lobo morreu em 1901, e Tristão Mariano da Costa em 1908. 0 paradigma do músico eclético, da qual ambos eram casos exemplares, chegava a um termo. Inaugurava-se uma nova fase, a do músico especialista. É claro, alguns músicos da antiga tradição continuariam por algum tempo dentro do ecletismo, mas este não era mais o paradigma hegemônico.

No entanto, eles mesmos iniciaram esta especialização, esta racionalização musical. Lembremos que Elias Alvares Lobo e Tristão Mariano da Costa organizaram o primeiro congresso de músicos. Elias Alvares Lobo foi também o criador do primeiro método de ensino nacional aprovado para as escolas públicas republicanas paulistas.

Em um período de intensas transformações, os músicos se perguntaram qual o papel que seria destinado à música, e, por conseguinte qual o papel que eles desempenhariam na sociedade. Mas se esta pergunta ecoava no círculo musical paulistano, as propostas não foram unânimes: o caminho foi de conflitos, lutas e opiniões divergentes. Cada qual procurava expor suas idéias da maneira que podia. Artigos na grande imprensa, artigos em publicações especializadas, conferências, concertos, todos os meios disponíveis eram utilizados.

0 quase despercebido prédio da Av. São João, atrás do Teatro Municipal tem muita história para contar. Foi alvo de muitas polêmicas e discussões, mesmo antes de ser fundado. Bem antes das aulas começarem. 


\section{Referências}

A MÚSICA PARA TODOS. Jornal musical. São Paulo, J.B. D'Arce, 1896-1899.

A PAULICEA: SEMANARIO ILLUSTRADO, CRÍTICO E LITERARIO. São Paulo, s/e, 1896. (IEB)

A PROVINCIA DE SÃO PAULO. São Paulo: Typographia d' A Provincia de São Paulo, 1875-1889.

ALMEIDA, F. M. de. Histórico do Conservatório Dramatico e Musical de São Paulo In: Relatório do Conservatório Dramatico e Musical de São Paulo. São Paulo: Typographia Fiume, 1931.

BOSI, E. Memória e sociedade: lembranças de velhos. 3a ed. São Paulo: Cia das Letras, 1994.

BURKE, P. Cultura popular na idade moderna. São Paulo: Companhia das letras, 1989.

CATANI, D. B. Educadores à meia-luz (um estudo sobre a Revista de Ensino da Associação Beneficente do Professorado Público de São Paulo: 1902-1918). 1989. Tese (Doutorado em educação) - FEUSP, São Paulo, 1989.

COSTA, A. M. da; SCHWARCZ, L. M. 1890-1914: no tempo das certezas. São Paulo: Cia das Letras, 2000.

GONÇALVES, J. Música na cidade de São Paulo (1850-1900): o circuito da partitura. Dissertação (Mestrado em história) FFLCH-USP, São Paulo, 1995.

GONDRA, J. G. Medicina, higiene e educação escolar. In: LOPES, E.M. T.; FARIA filho, L. M.; VEIGA, C. G. (org). 500 anos de educação no Brasil. 2 ed. Belo Horizonte: Autêntica, 2000. p. 519-550.

MORILA, A. P. Dando o tom: música e cultura nas ruas, salões e escolas da cidade de São Paulo (1870-1906) 2004. Tese (Doutorado em Educação) - Faculdade de Educação, Universidade de São Paulo, São Paulo, 2004.

Relatório do Conservatório Dramatico e Musical de São Paulo. São Paulo: Typographia Fiume, 1930- 931.

SERGL, M. J. Elias Alvares Lobo e a música em Itu. Dissertação (Mestrado em Artes) - ECA-USP, São Paulo, 1991.

VENTURA, R. Estilo Tropical: história cultural e polêmicas literárias no Brasil, 1870-1914. São Paulo: Cia das Letras, 1991.

\section{Notas}

1 Optou-se por manter a grafia original de todas as citações.

2 Apesar de Ventura colocar a polêmica como tentativa de se formar distinções teóricas, em um contexto da ciência evolucionista, ele não se esquece de dizer, entretanto, que esta polêmica teria também a influência dos desafios populares, tão comuns em diversos gêneros da época.

3 Provavelmente Carlos de Mello.

4 Entre eles: Joaquim Nabuco, Visconde de Taunay, Carlos de Laet, José do patrocínio, Lúcio de Mendonça, Graça Aranha, Rui Barbosa, Medeiros e Albuquerque, Oliveira Lima, Machado de Assis. (VENTURA, 1991, p.102 e 113).

5 Famoso Café-concerto na cidade do Rio de Janeiro.

6 As escolas italiana, francesa e alemã foram, respectivamente os modelos para a música erudita. É interessante notar que a maior parte dos compositores do período compuseram, ou tentaram compor óperas, expressão máxima da escola italiana.

7 A exemplo do que descreveu Peter BURKE $(1989$, p. 92) para a cultura popular européia, quando afirma que a Inquisição, no intuito de destruir a cultura popular, acabou eternizando-a nos autos inquisitoriais: "Outras atividades populares estão documentadas simplesmente porque as autoridades da Igreja ou do Estado estavam tentando eliminá-las. A maior parte do que sabemos sobre as rebeliões, heresias e feitiçarias do período foi registrada porque os rebeldes, hereges e bruxas foram levados a julgamento e interrogados."

8 Em debate com Oscar Lopes, Lima Barreto escreve: "tu que queres fugir à nossa grosseria, à nossa fealdade, à nossa pobreza agrícola, comercial e industrial, és um botafogo. Botafogano é o brasileiro exilado no Brasil; é o homem que anda, come, dorme, sonha em Paris." (COSTA, 2000, p. 151)

Ailton Pereira Morila é Bacharel em História pela Faculdade de Filosofia, Letras e Ciências Humanas da Universidade de São Paulo, Mestre e Doutor em Educação pela Faculdade de Educação da Universidade de São Paulo. Atualmente, é docente do Centro Universitário Central Paulista (UNICEP). Atua na área de História, com ênfase em História da Cultura, Educação e Música. 